\title{
EFFECT OF CARBODIIMIDE ON THE FATIGUE CRACK GROWTH RESISTANCE OF RESIN-DENTIN BONDS
}

\begin{abstract}
Recent studies have shown that ethyl-3-(3-dimethylaminopropyl) carbodiimide (EDC) inactivates endogenous dentin proteases, thereby preventing collagen degradation and improving the durability of adhesive bonds to dentin. Bond durability is routinely assessed by monotonic microtensile testing, which does not consider the cyclic nature of mastication. Objective: to characterize the effect of an EDC pretreatment on the fatigue crack growth behavior of resindentin bonds. Methods: Bonded interface Compact Tension (CT) specimens were prepared using a three-step etch-and-rinse adhesive and hybrid resin-composite. Adhesive bonding of the treated groups included a 1 min application of an experimental EDC conditioner to the acid-etched dentin. The control groups did not receive EDC treatment. The fatigue crack growth resistance was examined after storage in artificial saliva for 0,3 and 6 months. Results: There was no significant difference in the immediate fatigue crack growth resistance of the EDC-treated and control groups at 0 months. However, after the 3 and 6 months storage periods the EDC-treated groups exhibited significantly greater $(\mathrm{p} \leq 0.05)$ fatigue crack growth resistance than the control specimens. Significance: Although the EDC treatment maintained the fatigue crack growth resistance of the dentin bonds through 6 months of storage, additional studies are needed to assess its effectiveness over longer periods and in relation to other cross-linking agents.
\end{abstract}

Key Words: collagen; cross-linker; dentin bonding agents; durability; EDC; endogenous proteinases; fatigue crack growth; fracture 


\section{INTRODUCTION}

Contemporary bonding procedures used in the placement of resin-composite restorations can cause exposure and activation of endogenous dentin proteases [1]. This process causes gradual destruction of poorly infiltrated collagen fibrils within the hybrid layers of adhesive bonds to dentin [2,3]. Degradation of collagen within the hybrid layer can compromise the durability of adhesive bonds and facilitate a reduction in bond strength over time.

Manufacturers have simplified etch-and-rinse adhesives from three-step (involving etchant, primer and adhesive) to two-step systems (etchant and adhesive) by combining hydrophilic primers with hydrophobic adhesives with various solvents. But with this change the durability of resin-dentin bonds has decreased [2]. More recently, phosphoric acid etchants have been replaced by incorporating acidic monomers into a solvated adhesive to create single-step, self-etching adhesives. Application of both etch-and-rinse and self-etch adhesives causes activation of matrix-metalloproteinases (MMP)s and cysteine cathepsins [e.g. 4-7]. These are host-derived proteolytic enzymes that are bound to the dentin collagen matrix. When uncovered by etching, the MMPs slowly solubilize the collagen fibrils [1] and remain active even after resin-infiltration. Apparently, the time-dependent degradation of the hybrid layer is most evident in the use of etch-and-rinse adhesives [8].

Several strategies are being explored for preventing enzymatic degradation of the dentin collagen and to address the concerns related to the poor durability of resin-bonded dentin interfaces. Tjäderhane et al. [9], Montagner et al. [10] and Sabatini and Pashley [11] have recently reviewed the current understanding of collagen degradation and have discussed the relative merits/drawbacks of the techniques under exploration. One of the foremost approaches for inactivation of the dentin proteases involves using cross-linking agents. Covalent cross-links 
produced with exogenous cross-linkers (e.g. glutaraldehyde, grape seed extract and carbodiimides) inactivate the active sites of dentin proteases by reducing the molecular mobility of the active site or by changing negatively charged ionized carboxyl groups into positively charged amides [9]. Of the current crosslinkers, carbodiimide, has some attractive qualities, including very low cytotoxicity, and an ability to preserve dentin bond strength within clinically acceptable treatment times $[12,13]$.

Mazzoni et al. [14] recently reported promising results on the use of an EDC conditioning treatment in stabilizing dentin bonds. They evaluated the microtensile strength of dentin bonds for two different etch-and-rinse systems (Optibond FL and Adper Scotchbond Multi-Purpose) and assessed the degradation over a 12-month period. The EDC treatment consisted of exposing the etched dentin to a $0.3 \mathrm{M}$ EDC solution for 1 min prior to bonding. In comparison to the control groups, the EDC treated samples exhibited between 25 and $35 \%$ higher bond strengths after 12 months storage. A related study by the group [15] using zymography showed that the EDC treatment was successful in inactivating dentin gelatinases, thereby preventing degradation of the collagen.

While bond strength is an important metric of performance, resin-dentin bonded interfaces are subjected to cyclic loading and thus may undergo failure by fatigue and/or fatigue crack growth. Fatigue failures are considered of substantial importance to the success of restoratives [e.g. 16, 17]. Yet, studies in this area are scant and the contribution of fatigue to resin-dentin bond failures has received rather limited attention overall [18-26]. If flaws are located within either the resin adhesive or the hybrid layer, e.g. as a result of hydrolysis or incomplete resin infiltration [27], then the interface durability depends on its resistance to the "propagation" of these defects via cyclic crack extension. However, progressive failure of the 
resin-dentin bonded interface by either cyclic or slow crack growth has not been addressed by the dental materials community.

Soappman et al. [28] proposed an approach for evaluating the fatigue crack growth resistance of resin-dentin bonds, but it has not been applied to assess the effectiveness of an EDC treatment on dentin bond durability. Therefore, the primary objective of this study was to evaluate the effect of an experimental EDC conditioning treatment applied during dentin bonding, on the fatigue crack growth resistance of the adhesive interface. The null hypotheses to be tested were that an EDC treatment (consisting of $0.5 \mathrm{M}$ and 1 min exposure) applied during dentin bonding (1) does not change the immediate fatigue crack growth resistance of the resin/dentin interface, and (2) has no effect on the fatigue crack growth resistance up to a 6 month period of storage.

\section{MATERIALS AND METHODS}

The specimens utilized for this approach involve sections of coronal dentin that were obtained from caries-free human third molars and obtained with informed signed consent. The teeth were obtained from participating clinics in Maryland with record of age (18 $\leq$ age $\leq 30$ yrs) according to an approved protocol (\#Y04DA23151). Each tooth was sectioned using a slicer/grinder (Chevalier Smart-H818II, Chevalier Machinery, Santa Fe Springs, CA, USA) with diamond abrasive slicing wheels (\#320 mesh abrasives) and copious water coolant. The sections were obtained from the mid coronal region (Fig. 1a) as necessary for the specimen geometry. The remaining materials used in the development of the specimens included a three-step etchand-rinse adhesive (Scotchbond Multipurpose, SBMP, 3M ESPE) and compatible resin composite (Z100, 3M ESPE). 
Bonded interface Compact Tension (CT) specimens were prepared from the dentin sections using a special molding technique that has been described in detail in previous studies $[28,29]$. Briefly, the dentin sections represented half of the completed CT specimen geometry (Fig. 1b). Adhesive bonding was performed to the occlusal aspect of the dentin sections, with the pulp side facing away from the bonded interface. The occlusal edge was etched for $15 \mathrm{sec}$ (SB $37 \%$ phosphoric etchant) and rinsed with water in preparation for bonding. Then the SBMP primer and adhesive were applied to the etched surface according to the manufacturer's recommendations. Thereafter, these sections were placed in a specially designed mold that enabled incremental application of the resin composite as necessary to complete the CT geometry. A thin Mylar sheet was placed at one end of the interface to introduce a molded notch as evident in Figure 1b. The composite was cured on both sides for $40 \mathrm{sec}$ using a quartztungsten-halogen light-curing unit (Demetron VCL 401, Demetron, CA, USA) with output intensity of $600 \mathrm{~mW} / \mathrm{cm}^{\wedge} 2$ and with tip diameter wider than $10 \mathrm{~mm}$. Power emission of the curing light was measured and validated using a PM10 thermopile (Coherent, Santa Clara, CA) attached to a Fieldmate meter (Coherent) calibrated to NIST standards. The bonded sections were released from the mold and two holes were introduced using a miniature milling machine to facilitate the opening mode loading. A detailed description of the procedures used for specimen preparation has been presented previously [28].

The durability of the bonded interfaces was evaluated with and without an experimental treatment formulated to inactivate endogenous dentin proteases. For the treated specimens, the application of primer and adhesive was preceded by conditioning the demineralized collagen using an experimental solution of $0.5 \mathrm{M}$ ethyl-3-(3-dimethylaminopropyl) carbodiimide (EDC) for $60 \mathrm{sec}$. The specimens were then rinsed with water $(15 \mathrm{sec})$ and then lightly blotted. The 
remainder of the specimen preparation process was identical to that for those specimens without EDC. Following the aforementioned procedures, the specimens were placed within a phosphatebuffered artificial saliva at $37^{\circ} \mathrm{C}$ until further evaluation. A total of 36 specimens were prepared overall and consisted of an equal number of non-cross-linked control and cross-linked specimens (that received EDC treatment). The fatigue crack growth resistance of the specimens was evaluated after a storage period of 0,3 or 6 months, resulting in six specimens in each cell (treatment and time). Those specimens evaluated at 0 months (i.e. without storage) are considered to represent the "immediate" fatigue crack growth resistance and were tested after a period of at least 48 hours from the date of preparation.

The CT specimens were subjected to cyclic Mode I loading using a universal testing system (EnduraTEC Model ELF 3200, Minnetonka, MN, USA) with load capacity and sensitivity of $225 \mathrm{~N}$ and $\pm 0.01 \mathrm{~N}$, respectively. All experiments were performed within a bath of Hanks Balanced Salt Solution (HBSS) at room temperature (pH 7.4). The loading was applied under load control actuation, a frequency of $5 \mathrm{~Hz}$ and stress ratio (R) of 0.1 . Measurement of the crack length was accomplished using an imaging system that consisted of a microscope (Optem zoom 70x1 391940, QIOPTIQ, Luxembourg) and CCD camera. Sequential measurements of the crack length were used to estimate the incremental crack extension $(\Delta a)$ as a function of the loading cycles in the increment $\Delta \mathrm{N}$. In general, the increment of cyclic loading ranged from $5 \leqslant$ $\Delta \mathrm{N} \leqslant 30 \mathrm{k}$ cycles and the increment of crack growth extended from $0.02 \leqslant \Delta \mathrm{a} \leqslant 0.15 \mathrm{~mm}$. Cyclic loading was continued until the specimen underwent complete fracture. These procedures have been used previously for evaluating the resin-dentin bonded interface [28, 29] and the fatigue crack growth resistance of dentin [30, 31]. 
The fatigue crack growth experiments provided measurements of crack length as a function of the cyclic loading history for each of the specimens evaluated. The data was used to determine the incremental crack growth rate $(\Delta \mathrm{a} / \Delta \mathrm{N})$ and the corresponding stress intensity range $(\Delta \mathrm{K})$ over the total length of crack extension achieved. For the resin/dentin inset $\mathrm{CT}$ specimens the stress intensity range was estimated as a function of crack length according to

$$
\Delta \mathrm{K}=\frac{\Delta \mathrm{P}}{\mathrm{B} \sqrt{\mathrm{W}}}\left(0.1133+0.0841 \alpha+0.3859 \alpha^{2}\right)
$$

where $\Delta \mathrm{P}$ is the opening load range $\left(\mathrm{P}_{\max }-\mathrm{P}_{\min }\right), \mathrm{B}$ is the thickness of the specimen, $\mathrm{W}$ is the distance between the center of the loading points and free boundary in front of the crack, and $\alpha=$ $\mathrm{a} / \mathrm{W}$ is the ratio of the average crack length to the in-plane specimen width (Fig. 1b). The incremental crack growth rate was then plotted in terms of the stress intensity range for each specimen to assess the fatigue crack growth history and important parameters defining the resistance to cyclic crack growth.

According to the distribution of data, the threshold stress intensity range $\left(\Delta \mathrm{K}_{\mathrm{th}}\right)$ was estimated at the onset of cyclic crack growth, which represents the minimum stress intensity necessary for cyclic crack extension. The steady-state portion of the fatigue crack growth responses was also identified and modeled using the Paris Law [32] according to

$$
\frac{\mathrm{da}}{\mathrm{dN}}=\mathrm{C}(\Delta \mathrm{K})^{\mathrm{m}}
$$

where $\mathrm{C}$ and $\mathrm{m}$ are the fatigue crack growth coefficient and exponent, respectively. The average values of these two parameters were determined for each group of specimens. Significant differences in the fatigue crack growth parameters resulting from EDC treatment and storage time were identified using a one-way analysis of variance (ANOVA) with Tukey's HSD; significance was identified by $\mathrm{p} \leq 0.05$. The fatigue crack growth distributions were compared to 
establish significant differences between the groups using the Wilcoxon Rank Sum test with the critical value (alpha) set at 0.05 .

Selected fractured specimens were evaluated via Scanning Electron Microscopy (SEM) in secondary electron imaging mode using a scanning electron microscopy (FEI Model Nova NanoSEM 450; Hillsboro, OR, USA). Prior to the SEM analysis, the specimens were dehydrated in an ascending ethanol series (70-100\%), fixed in hexamethyldisilazane, and then sputtered with gold/palladium to enhance conductance of the hard tissue and resin adhesive. The fracture surfaces were inspected to identify any potential mechanisms of degradation or other factors contributing to the fatigue crack growth behavior.

The additional fractured specimens were prepared for analysis using Transmission Electron Microcopy (TEM) according to the protocol of Tay et al. [33]. All specimens were completely demineralized in 8 mole/L formic acid buffered with sodium formate to $\mathrm{pH} 2.5$. After demineralization, the specimens were fixed in Karnovsky's fixative $(2.5 \%$ glutaraldehyde and $2 \%$ paraformaldehyde in 0.1 mole/L cacadylate buffer, $\mathrm{pH} 7.3$ ) for a minimum of $1 \mathrm{hr}$ and rinsed thoroughly with fresh 0.1 mole/L sodium cacodylate buffer. Post-fixation was performed with $1 \%$ osmium tetroxide in 0.1 mole/L sodium cacodylate buffer $(\mathrm{pH} 7.3)$ for $1 \mathrm{hr}$ at room temperature. Then the specimens were dehydrated in an ascending ethanol series (30\% to $100 \%$ ), immersed in propylene oxide as a transition fluid, and embedded in epoxy resin (TAAB 812 resin, TAAB Laboratories, Aldermaston, UK) at $60^{\circ} \mathrm{C}$ for $48 \mathrm{hrs}$. After resin embedding two $2 \times 2 \mathrm{~mm}$ blocks were trimmed and re-embedded in epoxy resin to ensure proper orientation of the resin-dentin interface. Following initial screening of all semi-thin sections from each group, representative 1 x $1 \mathrm{~mm}$ ultrathin sections about $90 \mathrm{~nm}$ thick were prepared with an ultramicrotome (Reich Ultracut, Leica, Vienna, Austria) using a diamond knife (Diatome, 
Bienne, Switzerland) and collected on 100-mesh copper grids (TAAB Laboratories). Grids were double stained with $2 \%$ uranyl acetate for $10 \mathrm{~min}$, followed by lead citrate for an additional 5 min. After drying, the stained sections were examined with a Phillips EM208S (Eindhoven, The Netherlands) at $80 \mathrm{KV}$.

\section{RESULTS}

A representative fatigue crack growth response resulting from cyclic crack extension within a bonded interface CT specimen is shown in Figure 2a; the results in this figure correspond to a specimen that received EDC treatment and was evaluated without storage in artificial saliva (i.e. at 0 months). The threshold stress intensity range $\left(\Delta \mathrm{K}_{\mathrm{th}}\right)$ is highlighted at the onset of incremental crack growth, as well as the Paris Law exponent, which quantitates the slope of the steady-state response. The fatigue crack growth responses for all of the EDC treated specimens evaluated without storage are shown in Figure $2 \mathrm{~b}$, along with the responses obtained for the control group. According to the Wilcoxon Rank Sum test, there was no significant difference between the fatigue crack growth distributions of the control and EDC-treated specimens $(Z=-0.20 ; p=0.85)$ that were evaluated without storage in artificial saliva.

The fatigue crack growth distributions obtained from the specimens evaluated without storage (at 0 months) were used in estimating the corresponding fatigue crack growth parameters. The mean and standard deviation of the values obtained for the control and EDCtreated specimens are listed in Table 1 . Note that only the mean is presented for the crack growth coefficient $(\mathrm{C})$ due to the comparatively large variation in this parameter. Considering the initiation of cyclic crack extension, there was no significant difference in the values obtained for 
the $\Delta \mathrm{K}_{\mathrm{th}}$ between the control and EDC-treated groups. Similarly, there was no significant difference $(p>0.05)$ in the Paris Law parameters $(m, C)$ between the two groups.

A comparison of the fatigue crack growth resistance of the control and EDC treated specimens after storage in artificial saliva is shown in Figure 3. Specifically, the responses obtained after 3 and 6 months of storage are shown in Figures $3 a$ and 3b, respectively. According to the Wilcoxon Rank Sum test, after 3 months storage the EDC-treated specimens exhibited significantly greater resistance to fatigue crack growth than the control group $(Z=-$ 2.44; $\mathrm{p}=0.02$ ). The EDC-treated group also exhibited significantly greater resistance to fatigue crack growth than the control group after 6 months storage as well $(Z=-3.95 ; p<0.0001)$.

The average values of the fatigue crack growth parameters for the four groups of specimens stored in artificial saliva are presented in Table 1. In regards to the initiation of cyclic crack extension, the $\Delta \mathrm{K}_{\mathrm{th}}$ for the control specimens was not significantly different from that of the EDC group after 3 months. However, after 6 months in artificial saliva the $\Delta K_{\text {th }}$ of the control specimens was significantly lower than that of the EDC-treated group. Considering the steady-state fatigue crack growth behavior, there was no significant difference in the Paris Law parameters ( $\mathrm{m}$ and $\mathrm{C}$ ) between the control and EDC groups after 3 months. Nevertheless, there were significant differences in both $\mathrm{m}$ and $\mathrm{C}$ between the control and EDC groups after 6 months. There were also significant differences in the results obtained for the control group at 6 months with respect to the immediate responses (i.e. at 0 months) and the results obtained after 3 months. In contrast to the control specimens, the Paris Law parameters obtained for the EDC group evaluated after 6 months of storage were not significantly different from those values obtained for the 0 or 3 month storage groups. 
Figure 4a compares the fatigue crack growth responses obtained for all of the control specimens in terms of the period of storage. It is important to note that there is a translation in data to the left with increasing period of storage, which signifies a reduction of the fatigue crack growth resistance. Indeed, the fatigue crack growth resistance of the control groups evaluated after 6 months was significantly lower than that for the group evaluated immediately after dentin bonding $(\mathrm{Z}=-4.71 ; \mathrm{p}<0.0001)$. A similar comparison of results for the three EDC groups as a function of storage period is shown in Figure 4b. As evident in this figure, there appears to be a general translation of the data to the left with increasing storage time. However, in comparison to the responses for the control groups (Fig. 4a) there appears to be a wider distribution in the responses of the EDC treated samples. A statistical comparison of the EDC data showed that the fatigue crack growth resistance evaluated after 6 months of storage was not significantly lower than that group evaluated immediately after dentin bonding $(Z=-1.30 ; p=0.19)$.

The fracture surfaces were evaluated using scanning electron microscopy (SEM) and exhibited regions of adhesive failure (in the resin-adhesive or hybrid layer) and cohesive failure in the resin-composite. There was a combination of both adhesive and cohesive failure in all fracture surfaces examined. Yet, a greater proportion of adhesive failure was apparent in the samples subjected to water storage, especially in those stored for 6 months. A quantitative analysis of the fracture surfaces was not possible due to the differences in crack length at fracture for each specimen and corresponding total fracture surface area. However, there were distinct features of importance. Representative micrographs obtained from the SEM analysis are shown in Figure 5; each of these views represents the dentin side of the fracture surface. Within the regions of adhesive failure, cyclic crack growth occurred primarily within and at the bottom of the hybrid layer, where the resin tags penetrate into the dentinal tubules. Micrographs obtained 
from the fracture surfaces of representative control and EDC treated specimens evaluated at 0 months are shown in Figures 5a and 5b, respectively. There are remnants of fractured resin tags clearly visible in these two micrographs, which appear very consistent in the two groups. There is a small degree of debonding evident between some of the tags and surrounding intertubular dentin, which is equally evident in the control and EDC-treated specimen. SEM micrographs detailing the fracture surfaces of representative control and EDC-treated specimens evaluated after 6 months storage are shown in Figure 5c and 5d, respectively. For the control specimen (Fig. 5c), the resin tags have undergone fracture above and below the fracture surface proper. Also evident, there are collagen fibril tethers located at the interface of the tubules and resin tags that are stretched and/or broken. These features were unique to the control specimens that underwent 6 months of storage. The fracture surfaces of specimens in the EDC groups evaluated after 3 (not shown) and 6 months of storage (Fig. 5d) appeared very similar to those evaluated at 0 months with no evidence of degradation.

Figure 6a shows a control dentin specimen that was never incubated in water at $37^{\circ} \mathrm{C}$ to age the dentin. It was also not subjected to cyclic loading to initiate crack growth. The hybrid layer is about $5 \mu \mathrm{m}$ thick and is very homogeneous with no evidence of voids. The dentinal tubules were cut obliquely, showing that the true depth of the resin tags cannot be seen. Note the single dentinal tubule in the underlying mineralized dentin (M).

Figure $6 \mathrm{~b}$ is a fractured specimen from the experimental group. It was treated with $0.5 \mathrm{M}$ EDC for 1 min just after acid-etching to cross-link all of the demineralized collagen in the hybrid layer, and their bound endogenous proteases. After bonding with Scotchbond Mult-Purpose (SBMP) and being aged for 3 months in $37^{\circ} \mathrm{C}$ water, a crack was propagated through the bonded interface of this CT specimen until it failed. The fracture plane was at the top of the hybrid layer 
(H). The fractured resin tag on the left remained in the tubule, while the tag on the right pulled out of the dentinal tubule. Figure $6 \mathrm{c}$ is a similar EDC-treated, SBMP bonded specimen that was aged in $37^{\circ} \mathrm{C}$ water for 6 months before being tested. The specimen fractured at the top of the hybrid layer leaving a resin tag in the tubule. Small dilations of the interfibrillar spaces are thought to represent plastic deformation of collagen fibrils in the hybrid layer created by tensile forces associated with crack propagation in this CT specimen. A higher magnification of the region above the right arrowhead in Fig. 6c is shown in Fig. 7d. This is not considered as degradation of collagen fibrils because the collagen fibrils retain their normal dimensions and heavy metal staining.

Figure 7 shows a control SBMP-bonded specimen that was not treated with EDC. This CT specimen was incubated in $37^{\circ} \mathrm{C}$ water for 3 months prior to interfacial tensile stress application by crack propagation. The left side of the specimen fractured at the top of the hybrid layer, while the right side failure half way through the hybrid layer $(\mathrm{H})$ that had a disrupted appearance. Figure $7 \mathrm{~b}$ shows that area in higher magnification. Note thin pieces of degraded collagen (arrow heads) and ghost-like irregular circular sheaths that are heavily stained. These may have undergone plastic deformation during testing [34]. Figure 7c is a similar control specimen that was aged for 6 months prior to testing. Note the extensive degradation of the top $20 \%$ of the hybrid layer. This is shown better in Fig. $7 \mathrm{~d}$ where empty voids filled with embedding epoxy resin indicate the complete degradation of collagen fibrils. Some fibrils are much thinner than normal, indicating protease degradation.

Figure 8 is a schematic of hybridized demineralized dentin. In Fig. 8a, the acid-etched dentin was treated with $0.5 \mathrm{M}$ EDC for $60 \mathrm{sec}$ to cross-link all collagen fibrils and their associated non-collagenous proteins such as matrix metalloproteinases (MMPs) and cathepsins. 
The collagen fibrils are represented by cross-hatched spaghetti-like fibrils that reinforce polymerized adhesive resin (black background). We speculate that these two compounds of the hybrid layer share tensile stresses equally. Figure $8 \mathrm{~b}$ shows that control specimens that were not cross-linked undergo slow degradation of collagen by endogenous proteases. Insoluble collagen is converted to soluble gelatin, which is replaced by water (white voids). Resin is lost when the collagen fibrils were lost. In degrading hybrid layers, tensile loads are not shared in parallel, but the loads are transferred in series to fewer and fewer collagen fibrils that ultimately fail.

\section{DISCUSSION}

Results from the experimental evaluation showed that there was no significant difference in the fatigue crack growth responses between the control and EDC-treated groups evaluated at 0 months. Therefore, the $0.5 \mathrm{M}$ EDC treatment for $1 \mathrm{~min}$ did not change the immediate fatigue crack growth resistance of the resin-dentin bonds, and the first null hypothesis must be accepted. After the 3 month and 6 month periods of aging there was a significant difference in the fatigue crack growth resistance between the control and EDC groups, indicating that the cross-linking treatment had an effect on the fatigue crack growth resistance of the resin-dentin bonds. That requires rejection of the second null hypothesis.

In comparing the fatigue crack growth responses for the control and treated groups that underwent aging (Fig. 3a and 3b), the control groups were found to exhibit significantly lower fatigue crack growth resistance than the EDC-treated groups after both periods of storage. There were also significant differences in the fatigue crack growth parameters between the control and EDC groups (Table 1). After 6 months of aging, the control group exhibited lower resistance to the initiation of cyclic crack extension (i.e. smaller $\Delta \mathrm{K}_{\mathrm{th}}$ ) than the cross-linked treatment group. 
While the results are statistically significant, they may be of limited clinically relevance as there is roughly less than $10 \%$ difference. After 6 months aging the control group also exhibited significantly larger fatigue crack growth exponent and coefficient than the EDC group, and in comparison to results for all groups evaluated at 0 and 3 months as well. The rise in $\mathrm{m}$ and $\mathrm{C}$ signify an increased sensitivity to the crack and stress intensity range, and a larger effective crack growth rate, respectively. Collectively these changes represent a reduction in resin-dentin bond durability, which did not occur to the EDC-treated groups within the 6-month evaluation period. The cross-linking treatment suppressed changes to the fatigue crack growth resistance and maintained the durability of the dentin bonds prepared using SBMP.

A careful review of the micrographs detailing the fracture surfaces (Fig. 5) provides some insight regarding the differences in fatigue responses between the control and EDC-treated groups. There was no difference apparent in the extent of resin penetration within the tubules of the control and EDC treated specimens (Fig. 5). In the absence of aging in artificial saliva, cyclic crack growth caused failure of the resin tags at the fracture surface, which was predominately at the bottom of the hybridized zone and its interface with dentin. However, after 6 months of aging the resin tags of the control specimens underwent pullout failure more frequently as evident in Figure $5 \mathrm{c}$ and fracture of resin tags adjacent to the fracture surface proper. Resin tags of the corresponding EDC-treated group (Fig. 5d) underwent failure nearly uniformly in the fracture plane, which indicates that the resin tags were effectively "anchored" tightly within the tubules. Hybrid layers consist of a demineralized zone of acid-etched dentin and resin tags that extend down into the open tubules. Liquid resin passes from the resin tags into the surrounding demineralized intertubular dentin, where they envelop collagen fibrils. The collagen fibrils serve as a system of nano-mechanical anchors for the resin tags after 
polymerization of the resin. It is not clear if the filaments seen radiating from the remnant resin tags (Fig. 5c) are degrading collagen fibrils, or resin that had enveloped collagen fibrils that degraded over time. Regardless, the larger degree of pullout and debonding between the tags and intertubular matrix of the aged controls suggest that collagen degradation was underway (as confirmed by the TEM analysis (Fig. 7)) and it facilitated preferential tag and matrix failure in the weakened locations across the hybrid layer thickness.

In a paper by Tay et al. [34], the authors attempted to compare the relative contribution of resin vs. collagen to microtensile bond strength by bonding resins to moist dentin vs. air-dried dentin. In moist bonding, the collagen fibrils were well-infiltrated and gave high microtensile bond strengths (57-62 MPa). However, the bonds made to dry dentin had significantly lower strength (25-27 MPa). When the bonds were examined by high resolution SEM and TEM it was observed that dry collagen fibrils were not enveloped by resin, showing that most of the measured bond strengths were due to the unreinforced resin. As dry collagen fibrils undergo hydrogen bonding to each other, they collapse upon themselves preventing resin infiltration. They do not create hybrid layers. Their low bond strength is due to resin adherence to dry, collapsed collagen, not a hybrid zone of collagen infiltrated by resin. Tay et al. [34] interpreted the difference in mechanical behavior of these two microstructures with a schematic that showed parallel loading of resin and collagen fibrils in moist bonds (that share stress across the composite of resin and collagen fibrils), but series-loading of resin and collagen fibrils in dry bonds (Fig. 8).

We speculate that something analogous to that occurs in resin-dentin bonds that are allowed to undergo hydrolytic degradation over 3-6 months in water, before cyclic loading. In regions of effective resin infiltration of the demineralized dentin collagen the hybrid layer 
undergoes series loading (Fig. 8a). But as the collagen fibrils are slowly degraded into gelatin and the gelatin is replaced by water, the resin undergoes plasticization over time. Under the application of mechanical loading the partially degraded collagen fibrils would become overstrained and unravel [34]. The resin polymer in regions of degradation would become less effectively reinforced and undergo transition from parallel- to localized series-loading (Fig. 8b). In the early stages of collagen degradation these degraded regions are rather small and sparsely distributed, indicating that the concept of series-loading does not apply uniformly across the entire bonded interface. Cyclic loading of these degraded hybrid layers could cause preferential growth of damage within the regions undergoing hydrolytic degradation, which would promote further degradation of the adhesive bonds at the fibril level, and accelerate the size and distribution of these defects. A reduction in fatigue crack growth resistance would be expected with this loss of reinforcement, which was noted in the non-cross-linked control specimens (Fig. $3)$.

The present investigation is the first to explore the effectiveness of a proposed strategy for preventing endogenous dentin proteases from improving dentin bond durability in terms of the fatigue crack growth resistance. Prior studies aimed at quantifying degradation of the bonded interface with aging have utilized microtensile tests and have, in general, assessed the changes in bond performance after 12 months storage [e.g. 14, 35-39]. Based on an analysis of the fatigue crack growth responses, significant differences were found between the apparent durability of the control and EDC groups after only 3 months (Fig. 3a). After 6 months of storage the average rate of cyclic crack extension in the control group was between four to eight times higher than in the EDC treated group! Thus, it appears that the fatigue crack growth resistance of the interface is more sensitive to degradation by dentin endogenous proteases than is microtensile strength. It 
is also more clinically relevant and should be employed in future evaluations concerning the effectiveness of potential strategies for improving dentin bond durability.

The importance of cyclic stresses and mechanical strain to collagen degradation is an area that has received little attention. There is some evidence that cyclic stresses may also contribute to the degree of MMP activity [40] and promoted changes in the degree of mineralization [41, 42]. Collagen molecules spontaneously form aggregates that are called collagen-fibrils. The collagen molecules are not oriented parallel to the fibrils, but are off-set at an angle (see Fig. 4E.vi in [43]) so that the C-terminal end of each collagen molecule reaches the surface. The Cterminal globular telopeptide sterically blocks access of MMP-8, a collagenase, to the susceptible leucine-glycine peptide bond of collagen. However, if that collagen is over strained, the Cterminal telopeptide may be displaced from that site, uncovering the leucine-glycine peptide bond to collagenase activity. This provides a mechanism for the effect of cyclic loading of poorly infiltrated collagen to over-strain unsupported collagen that, in turn, allows more degradation of collagen than could occur in well-infiltrated collagen. Additional studies addressing the potential for synergistic degradation of the interface involving mechanical fatigue and MMP activity appears warranted.

In addition to cross-linkers restricting the mobility of the active sites of MMPs as a way of reducing collagen degradation, cross-linkers are also known to increase the stiffness of collagen peptides. A critical step in collagenase attack on collagen is when collagenases bind to collagen and locally unwinds the triple helical collagen, allowing MMP-1 or -8 to bind the leucine-glycine peptide bond. If collagen is stiffened by cross-linking agents, it is too stiff to unwind, and the collagenase become ineffective [44]. 
There are some concerns/limitations to this investigation that are important to consider. Foremost, the difference in fatigue crack growth resistance was interpreted to result from collagen degradation within the hybrid layer of the control samples by endogenous dentin proteases and the effectiveness of the EDC treatment in preventing this process $[12,13]$. While the TEM analysis showed evidence of collagen degradation in the aged control samples after 6 months, the differences in MMP activity between the EDC and control groups were not quantified. Mazzoni et al. [14] demonstrated that treatment of etched dentin for 1 minute using a 0.3 M EDC solution resulted in roughly 25 to $35 \%$ higher bond strengths after 12 months of water storage. A complementary use of zymography by the group [14,15] provided proof that the EDC treatment completely inactivated dentinal gelatinases up to 12 months. The similarity in EDC treatment used here supports that same conclusion. Another potential limitation is that the evaluation was conducted with a single three-step etch-and-rinse adhesive system. Two-step systems are reportedly less stable $[14,45,46]$ and may present a greater challenge to the EDC treatment. These studies are currently underway. In addition, the crack growth responses of the bonded interface specimens were treated assuming that the behavior is dominated by cyclic mechanisms of crack extension. Due to the properties of the adhesive and collagen network, visco-elastic and/or visco-plastic deformation could have contributed to the process of crack extension, especially in those specimens that underwent collagen degradation. The contribution of time-dependent deformation to the failure of resin-dentin bonds is an important issue that deserves further attention.

The present evaluation consisted of evaluating the interface durability by cyclic loading after completion of an aging protocol. There is potential for acceleration of dentin collagen degradation by endogeneous proteases in response to cyclic loading and oral functions [47-49]. 
Cyclic stretching of the collagen fibrils with the hybrid layer and consequent water movement within regions of damage may facilitate MMP activity and limit the EDC treatment effectiveness. Lastly, there was a moderate (but not significant) reduction in the durability of the EDC-treated adhesive bonds after 6 months storage (Fig 4b). This may be related to polymer swelling and resin leaching that occurs after prolonged water/oral fluid sorption [14]. Additional studies are needed to assess the effectiveness of EDC treatments in maintaining the fatigue crack growth resistance of resin-dentin bonds over longer durations.

\section{CONCLUSION}

On the basis of the experimental results it was demonstrated that EDC pre-conditioning of acid-etched dentin for 1 min was successful in maintaining the fatigue crack growth resistance of resin-dentin bonds. There was no significant difference between the immediate fatigue crack growth resistance of the bonded interfaces prepared with or without the EDC conditioning. However, after both 3 and 6 months of storage in artificial saliva the dentin bonds receiving EDC pre-treatment exhibited significantly greater resistance to fatigue crack growth as evidenced by a lower incremental crack growth rate. Further studies are needed regarding the use of EDC treatments and the fatigue resistance of dentin bonds, especially with respect to other strategies being considered for preventing degradation of bond strength.

\section{ACKNOWLEDGEMENTS}

The authors acknowledge support from the National Institutes of Health (NIDCR R01 DE015306-06 P.I. Pashley) and the National Science Foundation (NSF DMR 1337727 Takacs). 
The authors also gratefully acknowledge 3M ESPE for their generous donation of bonding supplies and resin composite. 


\section{REFERENCES}

1. Pashley DH, Tay FR, Yiu C, Hashimoto M, Breschi L, Carvalho RM, Ito S. Collagen degradation by host-derived enzymes during aging. J Dent Res. 2004;83(3):216-21.

2. Breschi L, Mazzoni A, Ruggeri A, Cadenaro M, Di Lenarda R, De Stefano Dorigo E. Dental adhesion review: aging and stability of the bonded interface. Dent Mater. 2008;24(1):90-101.

3. Pashley DH, Tay FR, Breschi L, Tjäderhane L, Carvalho RM, Carrilho M, Tezvergil-Mutluay A. State of the art etch-and-rinse adhesives. Dent Mater. 2011;27(1):1-16.

4. Mazzoni A, Pashley DH, Nishitani Y, Breschi L, Mannello F, Tjäderhane L, Toledano M, Pashley EL, Tay FR. Reactivation of inactivated endogenous proteolytic activities in phosphoric acid-etched dentine by etch-and-rinse adhesives. Biomaterials. 2006;27(25):4470-6.

5. Nishitani Y, Yoshiyama M, Wadgaonkar B, Breschi L, Mannello F, Mazzoni A, Carvalho RM, Tjäderhane L, Tay FR, Pashley DH. Activation of gelatinolytic/collagenolytic activity in dentin by self-etching adhesives. Eur J Oral Sci. 2006;114(2):160-6.

6. Tay FR, Pashley DH, Loushine RJ, Weller RN, Monticelli F, Osorio R. Self-etching adhesives increase collagenolytic activity in radicular dentin. J Endod. 2006;32(9):862-8.

7. Tjäderhane L, Nascimento FD, Breschi L, Mazzoni A, Tersariol IL, Geraldeli S, TezvergilMutluay A, Carrilho MR, Carvalho RM, Tay FR, Pashley DH. Optimizing dentin bond durability: control of collagen degradation by matrix metalloproteinases and cysteine cathepsins. Dent Mater. 2013;29(1):116-35.

8. Hashimoto, M. A review - micromorphological evidence of degradation in resin-dentin bonds and potential preventional solutions. Journal of Biomedical Materials Research: Part B, Applied Biomaterials 2010;92:268-280.

9. Tjäderhane L, Nascimento FD, Breschi L, Mazzoni A, Tersariol IL, Geraldeli S, TezvergilMutluay A, Carrilho M, Carvalho RM, Tay FR, Pashley DH. Strategies to prevent hydrolytic degradation of the hybrid layer-A review. Dent Mater 2013; 29(10):999-1011.

10. Montagner AF, Sarkis-Onofre R, Pereira-Cenci T, Cenci MS. MMP inhibitors on dentin stability: A systematic review and meta-analysis. J Dent Res 2014; 93(8):733-743.

11. Sabatini C, Pashley DH. Mechanisms regulating the degradation of dentin matrices by endogenous dentin proteases and their role in dentin adhesion. A Review. Am J Dent 2014;27:203-214.

12. Bedran-Russo AKB, Vidal CMP, Santos PHD, Castellan CS. Long-term effects of carbodiimide on dentin matrix and resin-dentin bonds. . J Biomed Mater Res. Part B Applied Biomaterials 2010;94B:250-5. 
13. Tezvergil-Mutluay A, Mutluay MM, Agee KA, Seseogullari-Dirihan R, Hoshika T, Cadenaro M, et al. Carbodiimide cross-linking inactivates soluble and matrix-bound MMPs, in vitro. J Dent Res. 2012;91:192-6.

14. Mazzoni A, Angeloni V, Apolonio FM, Scotti N, Tjäderhane L, Tezvergil-Mutluay A, Di Lenarda R, Tay FR, Pashley DH, Breschi L. Effect of carbodiimide (EDC) on the bond stability of etch-and-rinse adhesive systems. Dent Mater. 2013;29(10):1040-7.

15. Mazzoni A, Apolonio FM, Saboia VP, Santi S, Angeloni V, Checchi V, Curci R, Di Lenarda R, Tay FR, Pashley DH, Breschi L. Carbodiimide inactivation of MMPs and effect on dentin bonding. J Dent Res. 2014;93(3):263-8.

16. Lohbauer U, Belli R, Ferracane JL. Factors involved in mechanical fatigue degradation of dental resin composites. J Dent Res 2013; 92(7):584-91.

17. Zhang Y, Sailer I, Lawn BR. Fatigue of dental ceramics. J Dent. 2013;41(12):1135-47.

18. Drummond JL, Sakaguchi RL, Racean DC, Wozny J, Steinberg AD.Testing mode and surface treatment effects on dentin bonding. J Biomed Mater Res. 1996;32(4):533-41

19. Frankenberger R, Krämer N, Petschelt A. Fatigue behaviour of different dentin adhesives. Clin Oral Investig. 1999;3(1):11-7.

20. Frankenberger R, Strobel WO, Krämer N, Lohbauer U, Winterscheidt J, Winterscheidt B, et al. Evaluation of the fatigue behavior of the resin-dentin bond with the use of different methods. J Biomed Mater Res B Appl Biomater 2003; 67:712-21.

21. Frankenberger R, Pashley DH, Reich SM, Lohbauer U, Petschelt A, Tay FR.

Characterisation of resin-dentine interfaces by compressive cyclic loading. Biomaterials 2005; 26(14):2043-52.

22. De Munck J, Braem M, Wevers M, Yoshida Y, Inoue S, Suzuki K, Lambrechts P, Van Meerbeek B. Micro-rotary fatigue of tooth-biomaterial interfaces. Biomaterials 2005; 26:114553.

23. Staninec M, Kim P, Marshall GW, Ritchie RO, Marshall SJ. Fatigue of dentin-composite interfaces with four-point bend. Dent Mater. 2008;24(6):799-803.

24. Belli R, Baratieri LN, Braem M, Petschelt A, Lohbauer U. Tensile and bending fatigue of the adhesive interface to dentin. Dent Mater. 2010;26(12):1157-65.

25. Mutluay MM, Yahyazadehfar M, Ryou H, Majd H, Do D, Arola D. Fatigue of the resindentin interface: a new approach for evaluating the durability of dentin bonds. Dent Mater 2013; 29(4):437-49. 
26. Mutluay MM, Zhang K, Ryou H, Yahyazadehfar M, Majd H, Xu HH, Arola D. On the fatigue behavior of resin-dentin bonds after degradation by biofilm. J Mech Behav Biomed Mater 2013; 18:219-31.

27. Liu Y, Tjäderhane L, Breschi L, Mazzoni A, Li N, Mao J, Pashley DH, Tay FR. Limitations in bonding to dentin and experimental strategies to prevent bond degradation. J Dent Res. 2011; 90(8):953-68.

28. Soappman MJ, Nazari A, Porter JA, Arola D. A comparison of fatigue crack growth in resin composite, dentin and the interface. Dent Mater. 2007; 23:608-14.

29. Zhang Z, Beitzel D, Mutluay M, Tay FR, Pashley DH, Arola D. On the durability of resindentin bonds: Identifying the weakest links. Dent Mater. (under review).

30. Bajaj D, Sundaram N, Nazari A, Arola D. Age, dehydration and fatigue crack growth in dentin. Biomaterials. 2006;27(11):2507-17.

31. Ivancik J, Majd H, Bajaj D, Romberg E, Arola D. Contributions of aging to the fatigue crack growth resistance of human dentin. Acta Biomater. 2012;8(7):2737-46.

32. Paris PC, Erdogan F. A critical analysis of crack propagation laws. J Basic Eng 1963;

D85:528-34.

33. Tay FR, Carvalho R, Sano H, Pashley DH. Effect of smear layers on the bonding of a selfetching primer to dentin. J Adhes Dent. 2000a;2(2):99-116.

34. Tay FR, Carvalho RM, Yiu CK, King NM, Zhang Y, Agee K, Bouillaguet S, Pashley DH. Mechanical disruption of dentin collagen fibrils during resin-dentin bond testing. J Adhes Dent. 2000b;2(3):175-92.

35. Sano H, Yoshikawa T, Pereira PN, Kanemura N, Morigami M, Tagami J, Pashley DH. Long-term durability of dentin bonds made with a self-etching primer, in vivo. J Dent Res. 1999;78:909-916.

36. Shono Y, Terashita M, Shimada J, Kozono Y, Carvalho RM, Russell CM, Pashley DH. Durability of resin-dentin bonds. J Adhes Dent. 1999;1:211-218.

37. Hashimoto M, Ohono H, Kaga M, Endo K, Sano H, Oguchi H. In vivo degradation of resindentin bonds in humans over 1 to 3 years. J Dent Res. 2000;79:1385-1391.

38. Osorio R, Pisani-Proenca J, Erhardt MC, Osorio E, Aguilera FS, Tay FR, Toledano M. Resistance of ten contemporary adhesives to resin-dentine bond degradation. J Dent. 2008;36(2):163-9. 
39. De Munck J, Van den Steen PE, Mine A, Van Landuyt KL, Poitevin A, Opdenakker G, Van Meerbeek B. Inhibition of enzymatic degradation of adhesive-dentin interfaces. J Dent Res. 2009 ;88(12):1101-6.

40. Toledano M, Aguilera FS, Yamauti M, Ruiz-Requena ME, Osorio R. In vitro load-induced dentin collagen-stabilization against MMPs degradation. J Mech Behav Biomed Mater. 2013; $27: 10-8$.

41. Toledano M, Aguilera FS, Sauro S, Cabello I, Osorio E, Osorio R. Load cycling enhances bioactivity at the resin-dentin interface. Dent Mater 2014; 30(7):e169-88.

42. Toledano M, Osorio E, Aguilera FS, Sauro S, Cabello I, Osorio R. In vitro mechanical stimulation promoted remineralization at the resin/dentin interface. J Mech Behav Biomed Mater $2014 ; 30: 61-74$.

43. Bertassoni LE, Orgel JPR, Antipova O, Swain MV. The dentin organic matrix-limitations of restorative dentistry hidden on the nanometer scale. Acta Biomaterialia 2012;8:2419-2433.

44. Chung L, Dinakarpandian D, Yoshida N, Lauer-Fields J, Fields GB, Visse R, Nagase N. Collagenase unwinds triple-helical collagen prior to peptide bond hydrolysis. EMBO J 2004;23:3020-3030.

45. De Munck J, Mine A, Poitevin A, Van Ende A, Cardoso MV, Van Landuyt KL, Peumans M, Van Meerbeek B. Meta-analytical review of parameters involved in dentin bonding. J Dent Res. 2012;91(4):351-7.

46. Peumans M, Kanumilli P, De Munck J, Van Landuyt K, Lambrechts P, Van Meerbeek B. Clinical effectiveness of contemporary adhesives: a systematic review of current clinical trials. Dent Mater. 2005;21(9):864-81.

47. Hebling J, Pashley DH, Tjäderhane L, Tay FR. Chlorhexidine arrests subclinical degradation of dentin hybrid layers in vivo. J Dent Res. 2005;84(8):741-6.

48. Carrilho MR, Geraldeli S, Tay F, de Goes MF, Carvalho RM, Tjäderhane L, Reis AF, Hebling J, Mazzoni A, Breschi L, Pashley D. In vivo preservation of the hybrid layer by chlorhexidine. J Dent Res. 2007;86(6):529-33.

49. Ricci HA, Sanabe ME, de Souza Costa CA, Pashley DH, Hebling J. Chlorhexidine increases the longevity of in vivo resin-dentin bonds. Eur J Oral Sci. 2010;118(4):411-6. 
Table 1 The average values for the fatigue crack growth parameters obtained from the experiments including the threshold stress intensity range $\left(\Delta \mathrm{K}_{\mathrm{th}}\right)$ and Paris Law constants $\left.(\mathrm{m}, \mathrm{C})\right)$. Results are presented for the specimens receiving EDC crosslinking treatment during bonding (EDC) and those that did not (Control) at the three periods of storage. For each parameter, the responses with different superscript letters are significantly different $(p \leq 0.05)$.

\begin{tabular}{c|c|c|c|c|c|c|} 
& \multicolumn{2}{|c|}{ 0 months } & \multicolumn{2}{c|}{ 3 months } & months \\
\hline Property & Control & EDC & Control & EDC & Control & EDC \\
\hline$\Delta \mathrm{K}_{\mathrm{th}}\left[\mathrm{MPa} \bullet \mathrm{m}^{0.5}\right]$ & ${ }^{\mathrm{a}} 0.50 \pm 0.02$ & ${ }^{\mathrm{a}} 0.51 \pm 0.02$ & ${ }^{\mathrm{a}} 0.47 \pm 0.03$ & ${ }^{\mathrm{a}} 0.48 \pm 0.03$ & ${ }^{\mathrm{b}} 0.45 \pm 0.02$ & ${ }^{\mathrm{a}} 0.49 \pm 0.03$ \\
\hline $\mathrm{m}$ & ${ }^{\mathrm{a}} 16.0 \pm 0.6$ & ${ }^{\mathrm{a}} 16.8 \pm 0.2$ & ${ }^{\mathrm{a}} 17.4 \pm 0.5$ & ${ }^{\mathrm{a}} 15.8 \pm 1.3$ & ${ }^{\mathrm{b}} 21.5 \pm 2.8$ & ${ }^{\mathrm{a}} 14.1 \pm 3.2$ \\
\hline $\mathrm{C}\left[(\mathrm{mm} /\right.$ cycle $\left.)\left(\mathrm{MPa} \bullet \mathrm{m}^{0.5}\right)^{-\mathrm{m}}\right]$ & ${ }^{\mathrm{a}} 1.54 \times 10^{-1}$ & ${ }^{\mathrm{a}} 6.95 \times 10^{-2}$ & ${ }^{\mathrm{a}} 6.83 \times 10^{-1}$ & ${ }^{\mathrm{a}} 5.87 \times 10^{-2}$ & ${ }^{\mathrm{b}} 1.41 \times 10^{1}$ & ${ }^{\mathrm{a}} 6.23 \times 10^{-3}$
\end{tabular}




\section{List of Tables and Figures}

Table 1 The average values for the fatigue crack growth parameters obtained from the experiments including the threshold stress intensity range $\left(\Delta \mathrm{K}_{\mathrm{th}}\right)$ and Paris Law constants $(\mathrm{m}, \mathrm{C}))$. Results are presented for the specimens receiving EDC crosslinking treatment during bonding (EDC) and those that did not (Control) at the three periods of storage. For each parameter, the responses with different superscript letters are significantly different $(\mathrm{p} \leq 0.05)$.

Figure 1 Schematic diagrams describing a) the location and orientation of coronal dentin sections obtained for the bonded interface specimens (outlined by the dashed line) and b) the inset Compact Tension (CT) specimen geometry for characterizing the fatigue crack growth resistance. The diagram highlights the dentin (D) and resin composite (C), and orientation of the opening mode load (P). Adhesive bonding was performed to the occlusal aspect of the dentin sections, with the pulp side facing away from the bonded interface.

Figure 2 Fatigue crack growth responses for specimens that were evaluated without long term storage (i.e. at 0 months). a) a representative response for an EDC treated specimen. Highlighted in this figure are the stress intensity threshold $\left(\Delta \mathrm{K}_{\mathrm{th}}\right)$ and the Paris Law exponent $(\mathrm{m})$. The Paris Law coefficient (C, not shown) is the $\mathrm{y}$-intercept of the steady-state response curve (i.e. at $\Delta \mathrm{K}=1 \mathrm{MPa} \bullet \mathrm{m}^{0.5}$ ). b) cumulative responses for all specimens in the control and EDC groups that were evaluated at 0 months.

Figure 3 A comparison of the fatigue crack growth responses for the control and EDC-treated groups after storage in artificial saliva. a) cumulative responses for the specimens evaluated after 3 months. b) cumulative responses for the specimens evaluated after 6 months.

Figure 4 A comparison of the fatigue crack growth responses and importance of the cross-linking treatment as a function of storage time. a) control specimens, and b) EDC treated specimens.

Figure 5 Representative micrographs obtained from the fracture surfaces resulting from fatigue crack growth as noted from an analysis via scanning electron microscopy. The fracture surfaces from representative specimens evaluated after 0 months storage are shown for a) SBMP control and b) SBMP w/EDC. Similarly, the fracture surfaces from representative specimens evaluated after 6 months are shown for c) SBMP control and d) SBMP w/EDC. The orientation of fatigue crack growth in all of the samples was from left to right. The overlying hybrid layer had a thickness equivalent to about two tubule diameters. TEMs of those hybrid layers are shown in Fig. 6. 
Figure 6a) is a control specimen that was bonded with Scotchbond Multi-Purpose (SBMP) but never incubated in water or subjected to cyclic loading. It serves as an intact unstressed control. It is a stained, nondemineralized specimen that shows an irregular bonded surface with resin composite particles in its resin tags. The hybrid layer $(\mathrm{H})$ shows no voids or other signs of degradation. M: mineralized underlying dentin beneath the hybrid layer, and A: resin adhesive that has penetrated within the lumens. b) An EDC-treated specimen that was bonded with SBMP and then incubated in $37^{\circ} \mathrm{C}$ water for 3 months before the CT specimen was stressed by crack propagation to failure. Failure occurred at the top of the hybrid layer $(\mathrm{H})$. The resin tag on the left fractured at the top of the hybrid layer, while the resin tag on the right pulled out of the dentinal tubule. There were no signs of collagen degradation. D: underlying mineralized dentin that was completely demineralized in the laboratory to facilitate thin section microtomy, A: resin adhesive. c) Another EDC-treated specimen that was bonded with SBMP and then incubated in 37으 $\mathrm{C}$ water for 6 months prior to cyclic loading. The specimen fractured at the top of the hybrid layer leaving a resin tag in place (arrow). There were voids within the hybrid layer (open arrowheads). D: Laboratory demineralized dentin beneath the hybrid layer, A: resin adhesive. d) a high magnification of the voids within the hybrid layer in the Fig. $6 \mathrm{c}$ above the right arrowhead. Although there are many voids, the collagen fibrils retained their normal diameter and took up heavy metal stains like normal collagen.

Figure 7Acid-etched control dentin (not treated with EDC) prior to bonding with SBMP. a) Shows a CT specimen incubated in $37^{\circ} \mathrm{C}$ water for 3 months prior to interfacial stressing of by cyclic crack propagation to failure. This is a stained, demineralized section showing failure along the surface of the hybrid layer $(\mathrm{H})$ and within the hybrid layer (open arrow). A: resin adhesive that has penetrated within the lumens. Fig. $7 \mathrm{~b}$ is a higher magnification view of $7 \mathrm{a}$. Although there was no degradation of the collagen fibrils of the hybrid layer, failure occurred along the weakest portion of the hybrid layer where there were multiple voids close together (open arrowheads). D: laboratory demineralized dentin. Fig. 7c is a stained, demineralized section of a CT specimen bonded with SBMP and incubated in water for 6 months before crack propagation through the interface. Pointer indicates extensive degradation of the surface of the hybrid layer. Arrow shows fractured resin tag. D: laboratory demineralized dentin. Fig. 7d is a high magnification of Fig. $7 \mathrm{c}$ beneath the pointer showing large voids between degraded collagen fibrils. Some collagen fibrils showed reduced diameter degradation (pointer).

Figure 8 Schematic diagram of resin-bonded dentin. a) During bonding, the acidetched experimental dentin A was pretreated with 0.5 M EDC for 60 sec followed by rinsing and moist bonding with Adper Scotchbond Multi-Purpose Plus. The (black) adhesive resin ( $\left.E_{2}\right)$ envelops collagen fibrils (cross-hatched) so that they share tensile stress in a parallel-loading manner. The black resin at the top of Figures 7(a) and (b) could be adhesive resin above the hybrid layer or resin tags. b) The collagen fibrils ( $E_{1}$ ) in the bottom half of the control (untreated) hybrid layer have been degraded by activated MMPs. These have slowly solubilized the insoluble collagen (cross-hatched) into soluble gelatin (clear fibrils). As gelatin is solubilized, it is 
replaced by water-filled voids (irregular white zones). In the absence of collagen fibrils, some regions exhibit series-loading where adjacent resin tags take most of the tensile stress and gelatin offers little resistance or reinforcement (Modified from Tay et al. [34] with permission). 


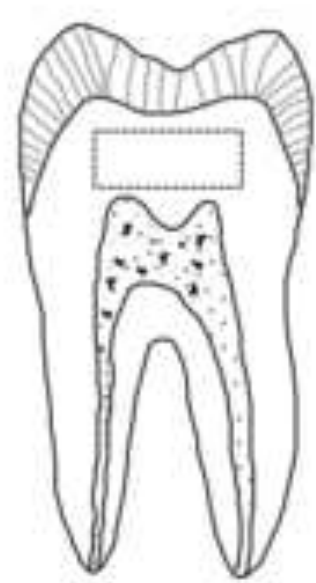

)

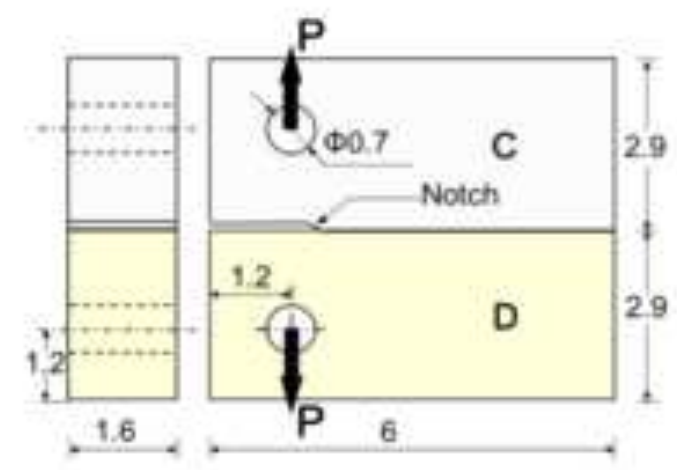

b)

Figure 1 Schematic diagrams describing a) the location and orientation of coronal dentin sections obtained for the bonded interface specimens (outlined by the dashed line) and b) the inset Compact Tension (CT) specimen geometry for characterizing the fatigue crack growth resistance. The diagram highlights the dentin (D) and resin composite (C), and orientation of the opening mode load (P). Adhesive bonding was performed to the occlusal aspect of the dentin sections, with the pulp side facing away from the bonded interface. 


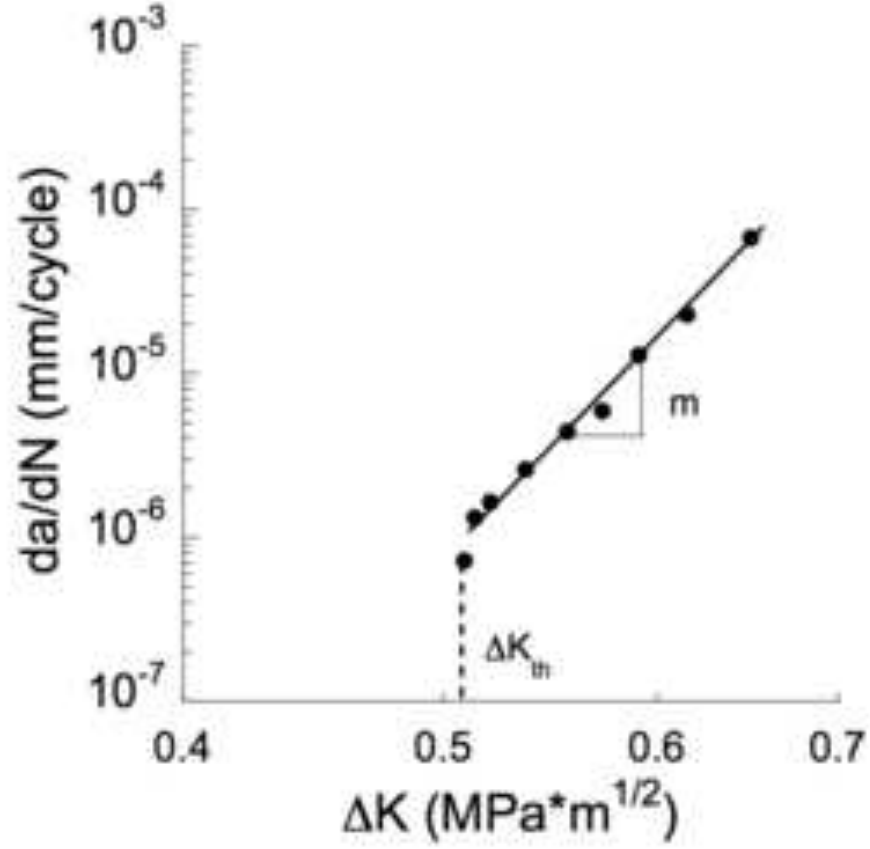

a)

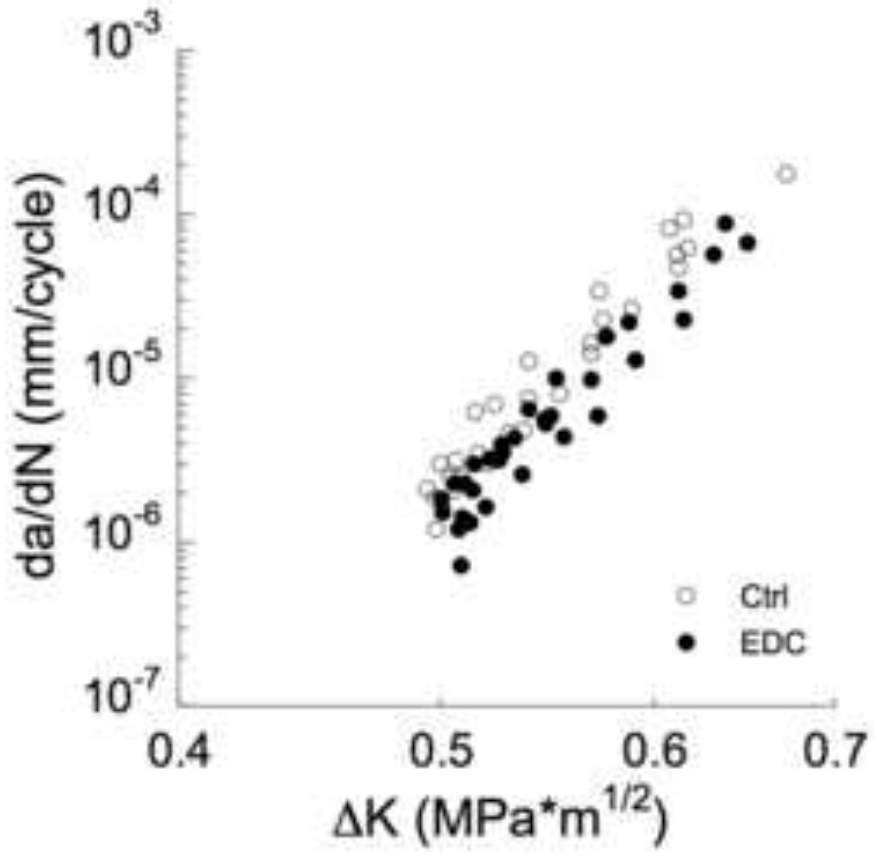

b)

Figure 2 Fatigue crack growth responses for specimens that were evaluated without long term storage (i.e, at 0 months). a) a representative response for an EDC treated specimen. Highlighted in this figure are the stress intensity threshold ( $\left.\Delta K_{\mathrm{B}}\right)$ and the Paris Law exponent (m). The Paris Law coefficient (C, not shown) is the $y$-intercept of the steady-state response curve (Le. at $\Delta K=1 \mathrm{MPa} \cdot \mathrm{m}^{05}$ ). b) cumulative responses for all specimens in the control and EDC groups that were evaluated at 0 months. 


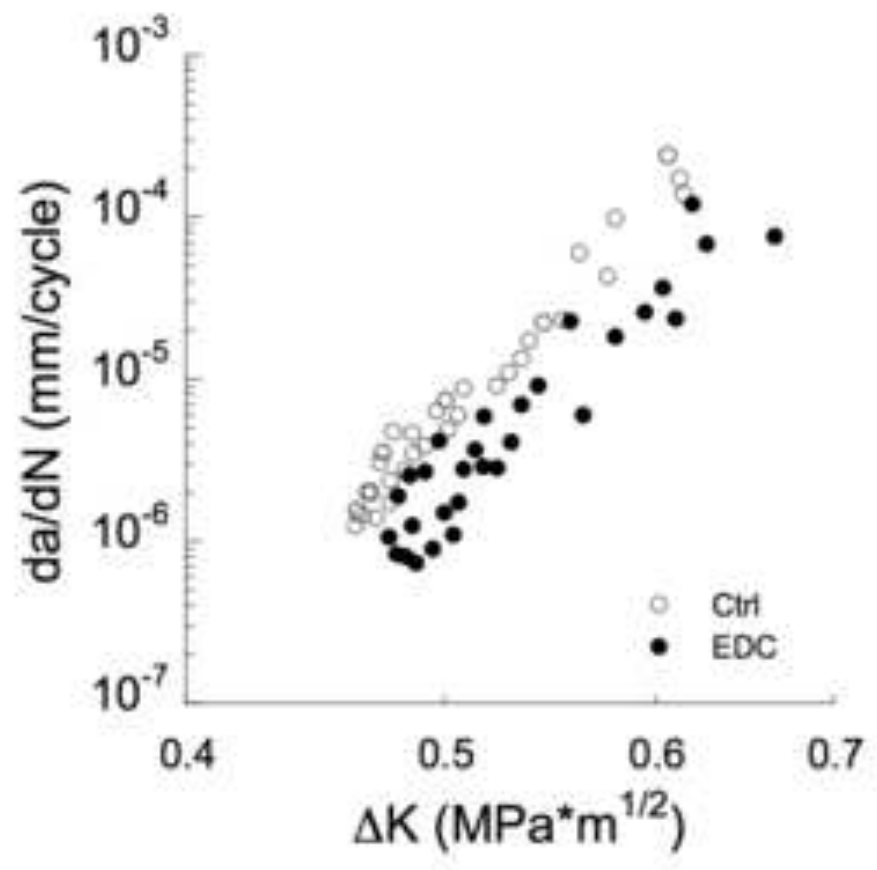

a)

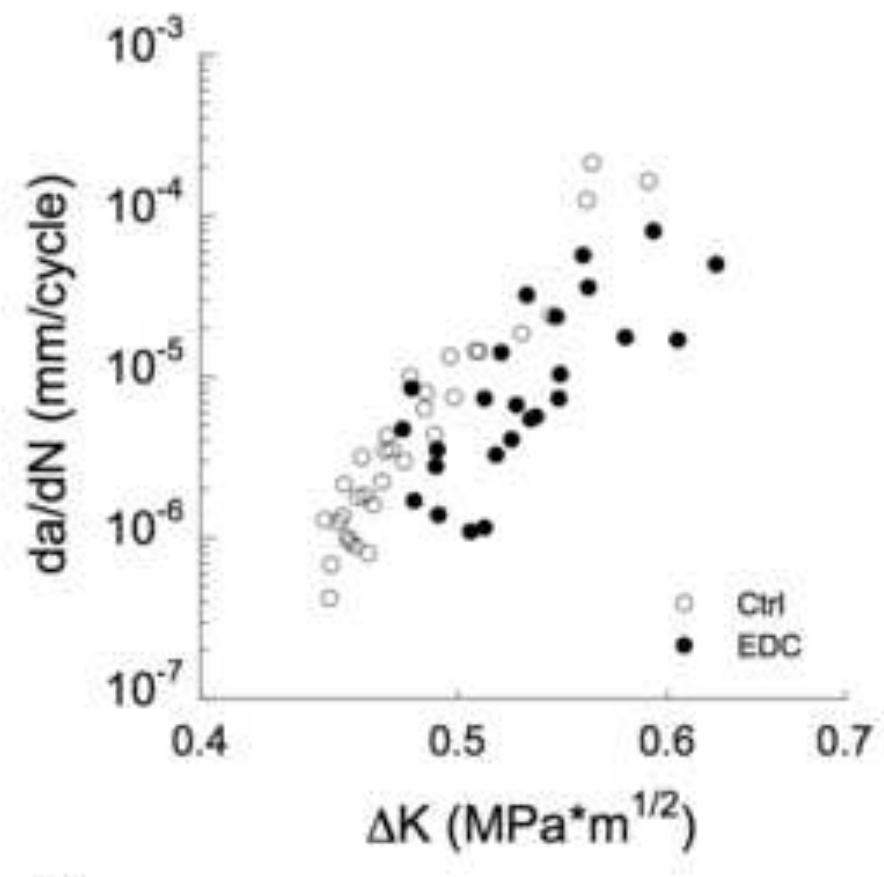

b)

Figure 3 A comparison of the fatigue crack growth responses for the control and EDC-treated groups after storage in artificial saliva. a) cumulative responses for the specimens evaluated after 3 months. b) cumulative responses for the specimens evaluated after 6 months. 


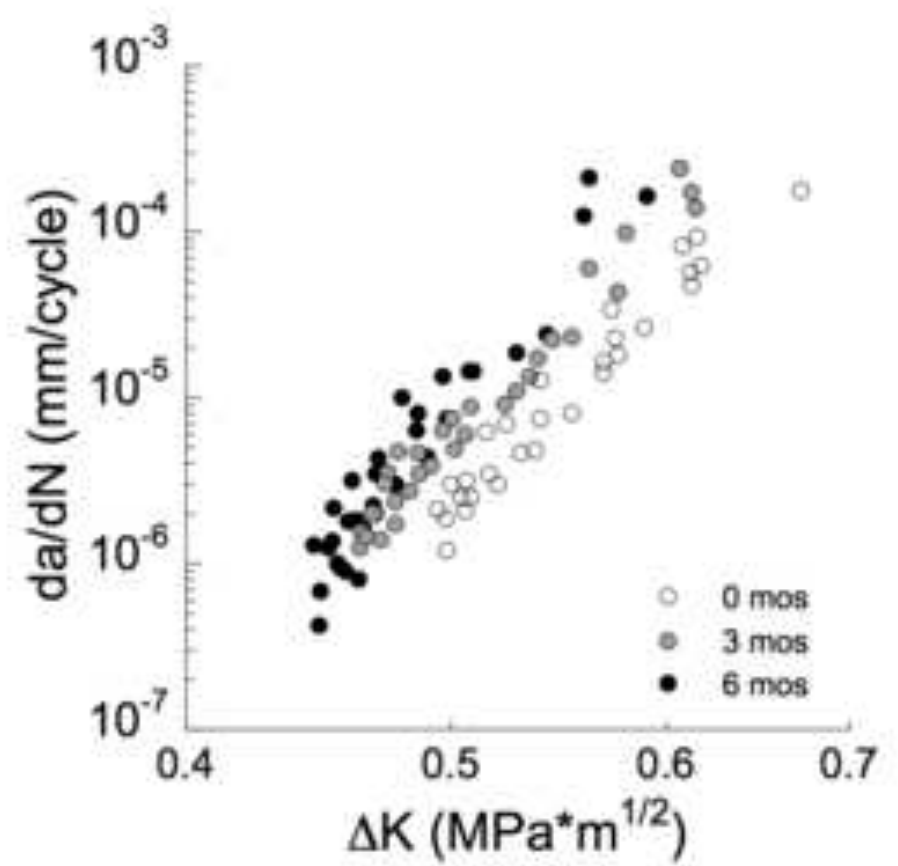

a)

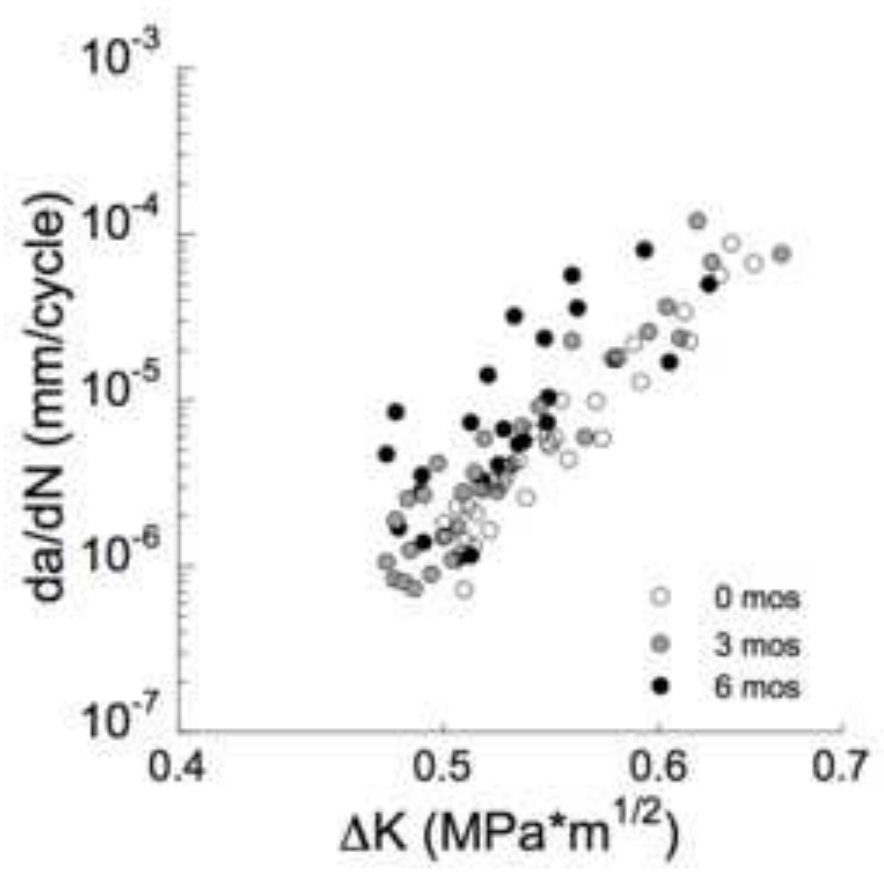

b)

Figure 4 A comparison of the fatigue crack growth responses and importance of the cross-linking treatment as a function of storage time. a) control specimens, and b) EDC treated specimens. 

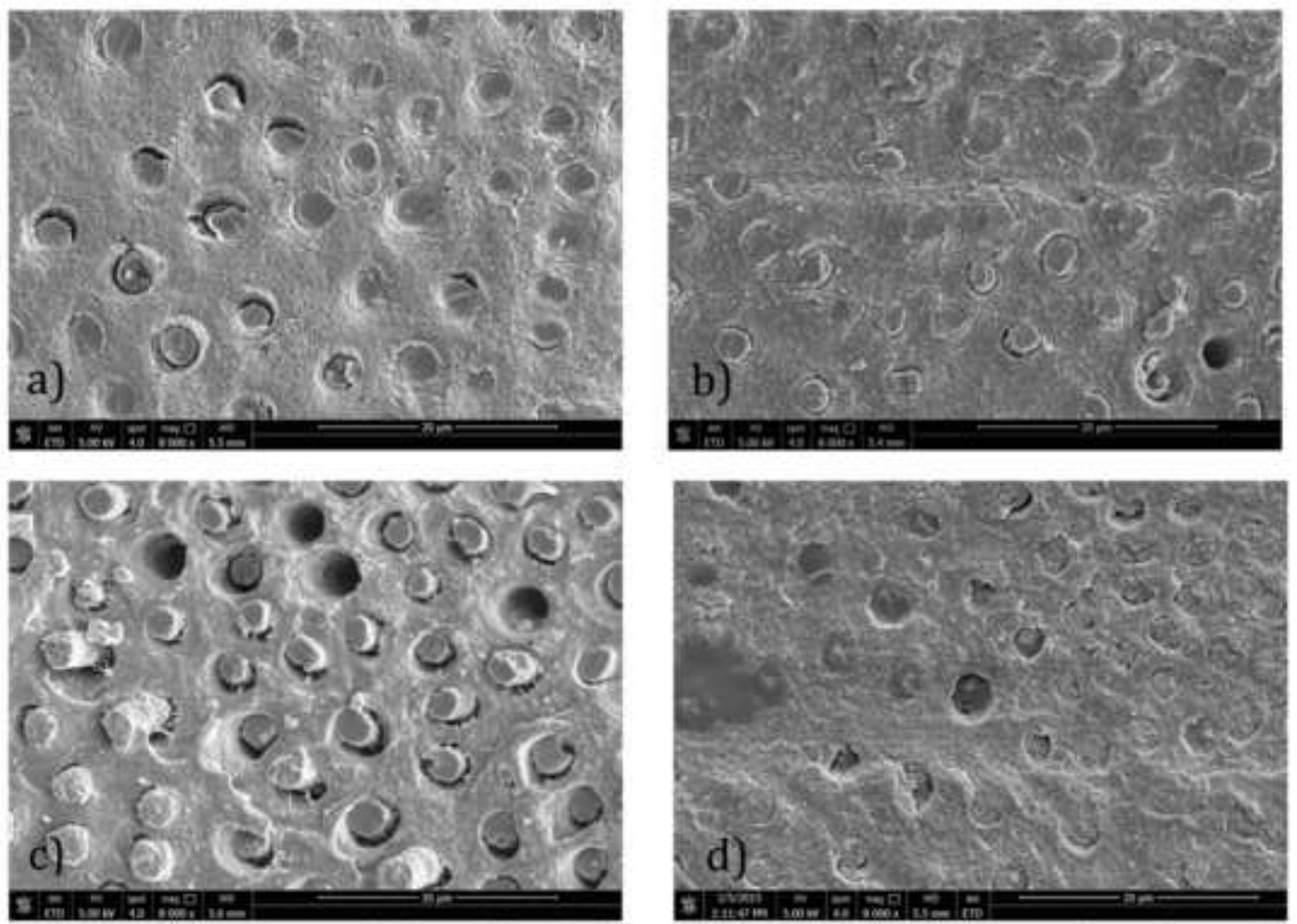

Figure 5 Representative micrographs obtained from the fracture surfaces resulting from fatigue crack growth as noted from an analysis via scanning electron microscopy. The fracture surfaces from representative specimens evaluated after 0 months storage are shown for a) SBMP control and b) SBMP w/EDC. Similarly, the fracture surfaces from representative specimens evaluated after 6 months are shown for c) SBMP control and d) SBMP w/EDC. The orientation of fatigue crack growth in all of the samples was from left to right. The overlying hybrid layer had a thickness equivalent to about two tubule diameters. TEMs of those hybrid layers are shown in Fig, 6. 
a

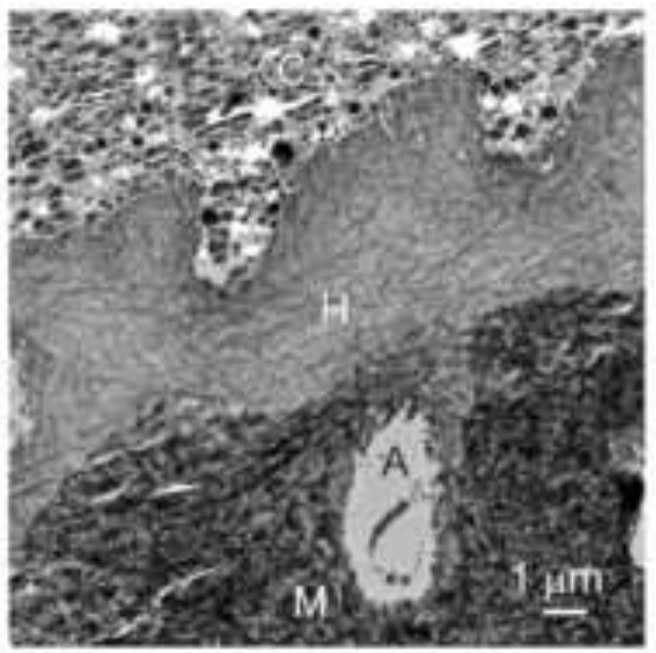

C

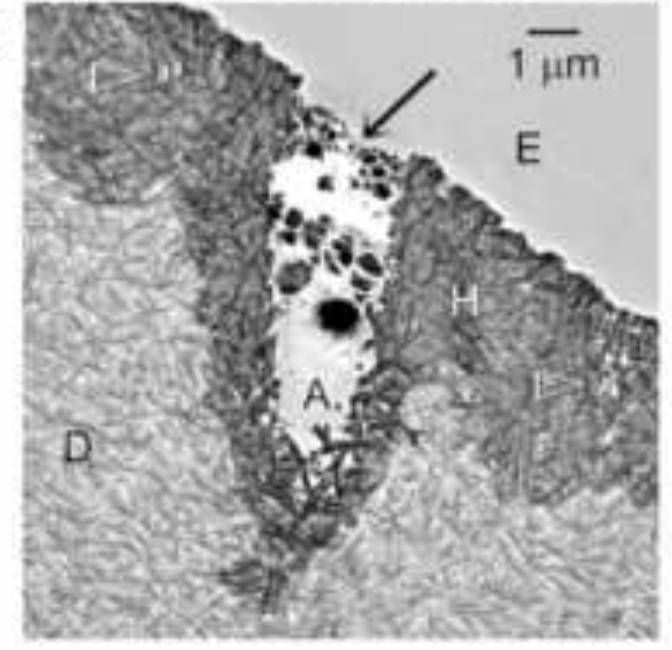

b

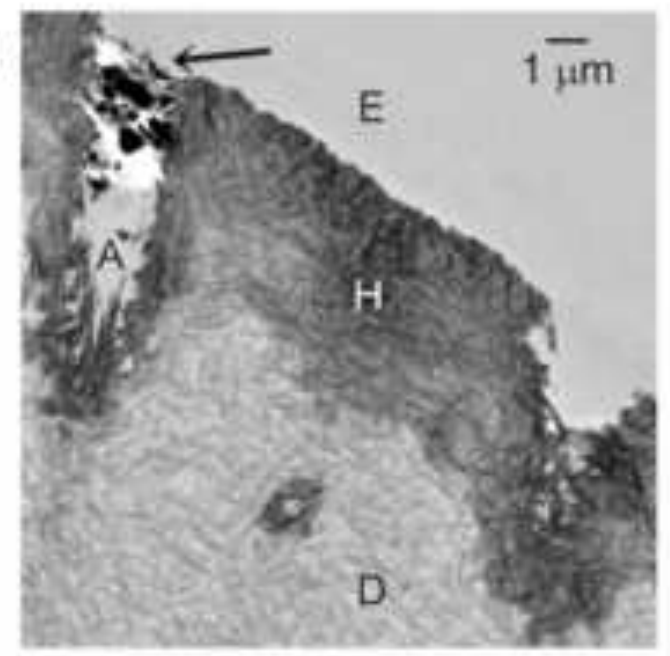

d

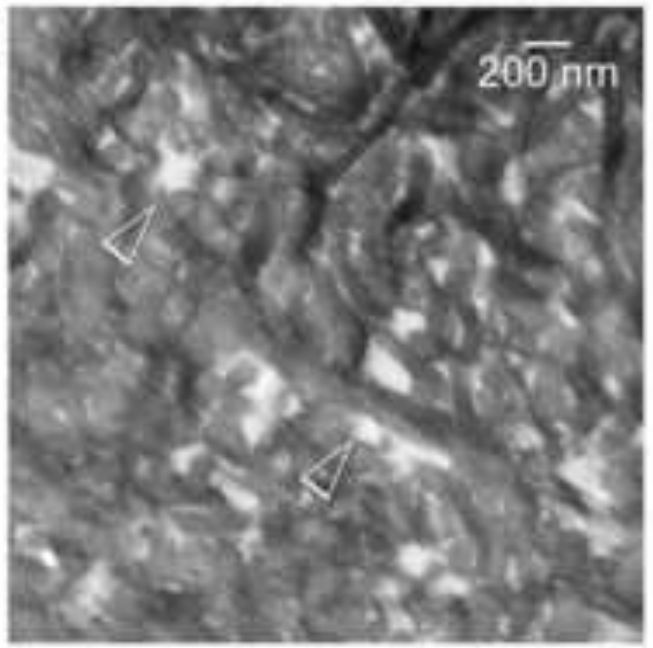

Figure 6a) is a control specimen that was bonded with Scotchbond Multi-Purpose (SBMP) but never incubated in water or subjected to cyclic loading. It serves as an intact unstressed control. It is a stained, nondemineralized specimen that shows an irregular bonded surface with resin composite particles in its resin tags. The hybrid layer $(\mathrm{H})$ shows no voids or other signs of degradation. M: mineralized underlying dentin beneath the hybrid layer, and A: resin adhesive that has penetrated within the lumens. b) An EDCtreated specimen that was bonded with SBMP and then incubated in $37^{\circ} \mathrm{C}$ water for 3 months before the CT specimen was stressed by crack propagation to failure. Failure occurred at the top of the hybrid layer $(\mathrm{H})$. The resin tag on the left fractured at the top of the hybrid layer, while the resin tag on the right pulled out of the dentinal tubule. There were no signs of collagen degradation. Di underlying mineralized dentin that was completely demineralized in the laboratory to facilitate thin section microtomy, A: resin adhesive. c) Another EDC-treated specimen that was bonded with SBMP and then incubated in $37^{\circ} \mathrm{C}$ water for 6 months prior to cyclic loading. The specimen fractured at the 
a

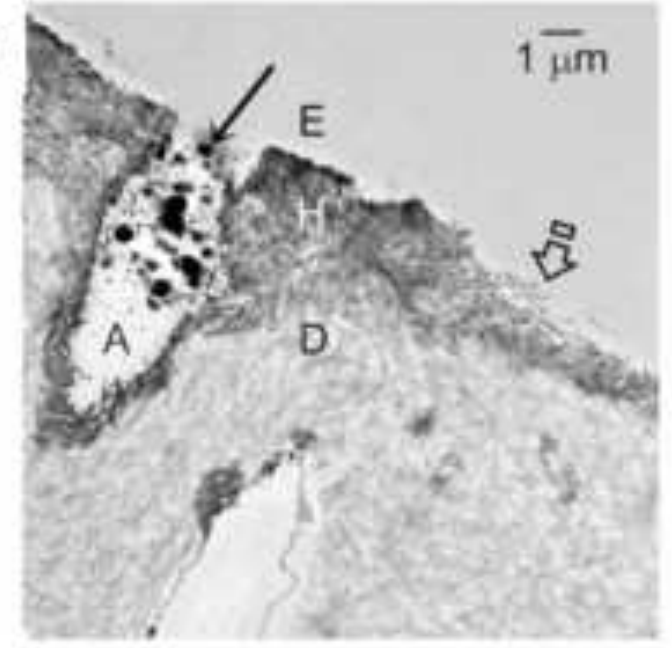

c

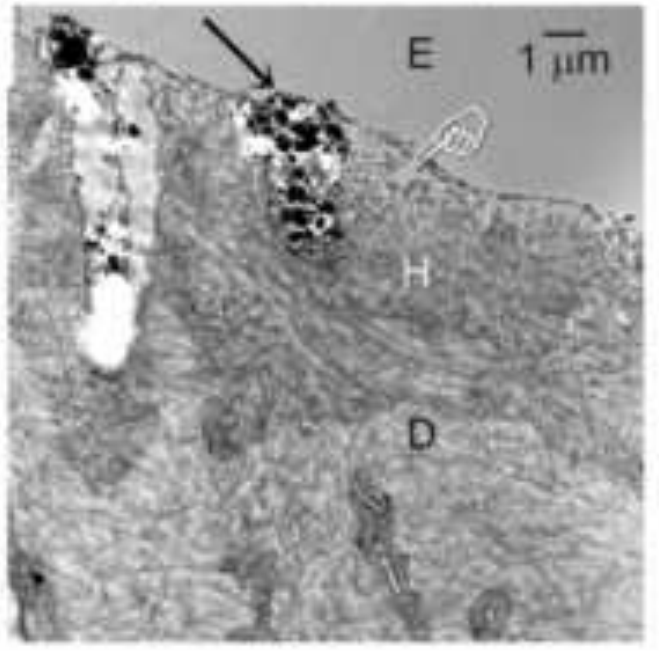

b

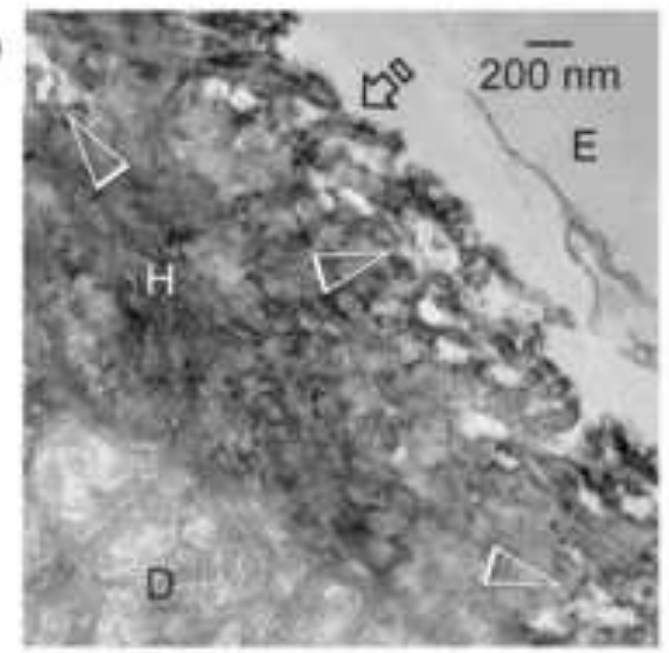

d

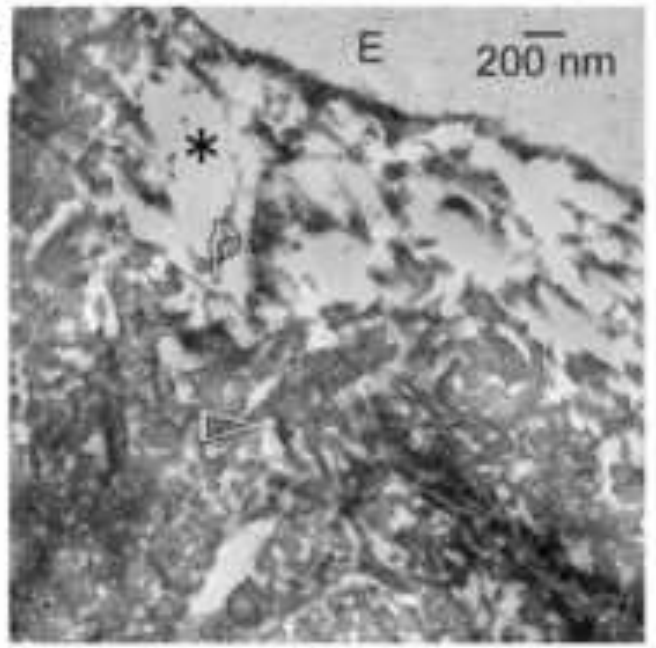

Figure 7Acid-etched control dentin (not treated with EDC) prior to bonding with SBMP.a) Shows a CT specimen incubated in $37^{\circ} \mathrm{C}$ water for 3 months prior to interfacial stressing of by cyclic crack propagation to failure. This is a stained, demineralized section showing failure along the surface of the hybrid layer $(\mathrm{H})$ and within the hybrid layer (open arrow). A: resin adhesive that has penetrated within the lumens. Fig. $7 \mathrm{~b}$ is a higher magnification view of $7 \mathrm{a}$. Although there was no degradation of the collagen fibrils of the hybrid layer, failure occurred along the weakest portion of the hybrid layer where there were multiple voids close together (open arrowheads). D: laboratory demineralized dentin. Fig. $7 \mathrm{c} \mathrm{is} \mathrm{a}$ stained, demineralized section of a CT specimen bonded with SBMP and incubated in water for 6 months before crack propagation through the interface. Pointer indicates extensive degradation of the surface of the hybrid layer. Arrow shows fractured resin tag. D: laboratory demineralized dentin. Fig, $7 \mathrm{~d}$ is a high magnification of Fig. $7 \mathrm{c}$ beneath the pointer showing large voids between degraded collagen fibrils. Some collagen fibrils showed reduced diameter degradation (pointer). 


\section{Figure}

Click here to download high resolution image

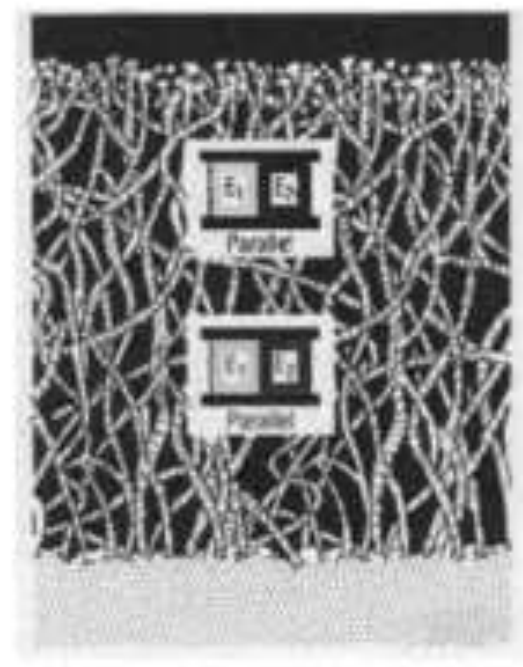

a)

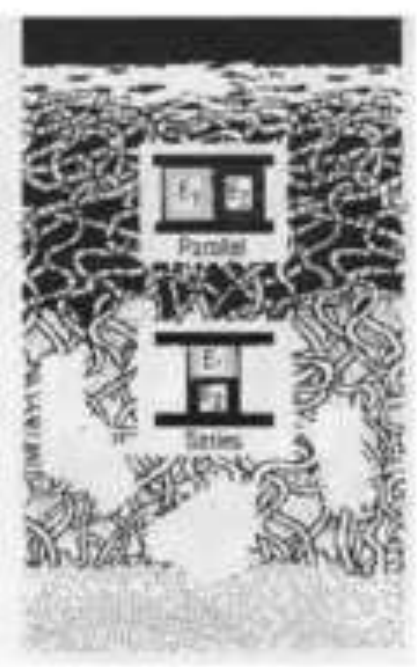

b)

Figure 8 Schematic diagram of resin-bonded dentin. a) During bonding the acid-etched experimental dentin A was pretreated with $0.5 \mathrm{M}$ EDC for $60 \mathrm{sec}$ followed by rinsing and moist bonding with Adper Scotchbond Multi-Purpose Plus. The (black) adhesive resin $\left(\mathrm{E}_{2}\right)$ envelops collagen fibrils (cross-hatched) so that they share tensile stress in a parallelloading manner. The black resin at the top of Figures $7(a)$ and $(b)$ could be adhesive resin above the hybrid layer or resin tags. b) The collagen fibrils $\left(\mathrm{E}_{1}\right)$ in the bottom half of the control (untreated) hybrid layer have been degraded by activated MMPs. These have slowly solubilized the insoluble collagen (cross-hatched) into soluble gelatin (clear fibrils). As gelatin is solubilized, it is replaced by water-filled voids (irregular white zones). In the absence of collagen fibrils, some regions exhibit series-loading where adjacent resin tags take most of the tensile stress and gelatin offers little resistance or reinforcement (Modified from Tay et al. [34] with permission). 